Article

\title{
Short-Term Chromium-Stress-Induced Alterations in the Maize Leaf Proteome
}

\author{
Rong Wang ${ }^{1, \dagger}$, Fei Gao ${ }^{2,3, \dagger}$, Bing-Qian Guo ${ }^{2}$, Ji-Chang Huang ${ }^{1}$, Lei Wang ${ }^{3, *}$ \\ and Yi-Jun Zhou ${ }^{2, *}$
}

1 College of Life Science, Fuyang Teachers College, Fuyang 236037, China;

E-Mails: wangrbnu@yahoo.com.cn (R.W.); huangjichang1988@126.com (J.-C.H.)

2 College of Life and Environmental Sciences, Minzu University of China, Beijing 100081, China; E-Mails: gaofei@muc.edu.cn (F.G.); guobingqian2050@163.com (B.-Q.G.)

3 Biotechnology Research Institute, Chinese Academy of Agricultural Sciences, Beijing 100081, China

$\dagger$ These authors contributed equally to this work.

* Authors to whom correspondence should be addressed; E-Mails: wanglei@caas.net.cn (L.W.); zhouyijun@muc.edu.cn (Y.-J.Z.); Tel./Fax: +86-10-8210-6134 (L.W.); +86-10-6893-2922 (Y.-J.Z.).

Received: 4 March 2013; in revised form: 25 April 2013 / Accepted: 15 May 2013 /

Published: 27 May 2013

\begin{abstract}
Soil contamination by chromium ( $\mathrm{Cr}$ ) has become an increasing problem worldwide as a result of extensive industrial activities. Chromium, especially hexavalent $\mathrm{Cr}$, impairs the growth and productivity of plants. Although it has been proposed that plants could modify their metabolism to adapt to $\mathrm{Cr}$ stress by reprogramming the expression of genes, especially those related to the antioxidant system, damage response, and electron transport chain, evidence at the protein expression level is lacking. To better understand the precise mechanisms underlying $\mathrm{Cr}$ phytoxicity and the plant response to $\mathrm{Cr}$ exposure, the time-course of changes in the protein expression profile induced by short-term hexavalent $\mathrm{Cr}$ exposure (1, 6 and $24 \mathrm{~h}$ ) were analyzed in maize leaves. Among the over 1200 protein spots detected reproducibly by two-dimensional electrophoresis (2-DE), 60 were found to be differentially accumulated during $\mathrm{Cr}$ stress treatment. Of the Cr-regulated proteins, 58 were identified using tandem mass spectrometry (MS/MS). The Cr-regulated proteins identified were mainly involved in ROS detoxification and defense responses $(26 \%)$, photosynthesis and chloroplast organization $(22 \%)$, post-transcriptional processing of mRNA and rRNA (12\%), protein synthesis and folding (10\%), the DNA
\end{abstract}


damage response $(5 \%)$, and the cytoskeleton $(3 \%)$. The possible involvement of these $\mathrm{Cr}$ stress-responsive proteins in $\mathrm{Cr}$ phytoxicity and the plant response to $\mathrm{Cr}$ exposure in maize is discussed, taking into consideration the information available from other plant models. Our results provide preliminary evidence that will facilitate understanding the molecular mechanisms underlying $\mathrm{Cr}$ toxicity in maize.

Keywords: maize; chromium; leaf; proteomics

\section{Introduction}

Heavy metal contamination in soil is a cause of major environmental hazards globally, and results primarily from increased industrial pollution, urban activities, and agricultural practices [1]. Heavy metal pollution negatively affects the growth and development of plants, leading to losses of agricultural yields and endangering human health when it enters the food chain.

As one of the most abundant elements, chromium (Cr) exists in nature in both trivalent (Cr III) and hexavalent (Cr VI) forms, of which the latter is more toxic. $\mathrm{Cr}$ (VI) is highly hazardous to human health through inhalation, skin contact, and ingestion, being highly toxic, carcinogenic and mutagenic to living organisms, even when present in very low amounts. Excessive amounts of chromium within plants cause stunted growth of shoots and roots [2,3], lead to chlorosis of leaves, cell membrane damage, changes in the activity of various antioxidant enzymes and diminished photosynthesis [4]. $\mathrm{Cr}$ compounds released into the environment represent one of the most serious heavy metal pollutants both worldwide and in China [5]. Cr contamination originates mainly from industrial operations, including stainless steel production, mining, pigment manufacturing, petroleum refining, leather tanning, wood preservation, textile manufacturing, pulp processing, and fungicide development $[5,6]$.

To cope with the detrimental effects of heavy metal accumulation, plants, like all other organisms, have evolved sophisticated mechanisms, including detoxification strategies based on chelation and subcellular compartmentalization [7]. First, plants exposed to elevated concentrations of heavy metal ions attempt to prevent or reduce uptake into root cells by restricting metal ions to the apoplast or by inhibiting root-to-shoot long-distance transport [8]; this mechanism occurs mainly in the root. Second, metal ions already in the cell are addressed using various storage and detoxification strategies, including metal chelation, transport, and sequestration into the vacuole. Finally, oxidative stress defense mechanisms are activated, with synthesis of stress-related proteins and signaling molecules.

Although the molecular and physiological mechanisms of plant responses to heavy metals, especially lead $(\mathrm{Pb})$ and cadmium $(\mathrm{Cd})$, have been focused upon in recent years, chromium $(\mathrm{Cr}$, especially $\mathrm{Cr}(\mathrm{VI})$ ) has attracted less attention from plant scientists [9], and the detoxification mechanism for chromium in plants is poorly understood [10]. The molecular mechanisms underlying plant responses to $\mathrm{Cr}$ stress and the defense-related signal transduction process have been investigated only partially. For example, a number of candidate genes potentially involved $\mathrm{Cr}$ tolerance were identified in four willow species using a cDNA-AFLP method [11]. The Cr (VI) stress response in roots has been analyzed at the transcriptomic and metabolomic levels in rice [12] and at the proteomic level in roots of Miscanthus sinensis [13]. 
Because of its economic importance, the wide range of its growing area, and the feasibility of combining extensive physiological, agronomic, and genetic studies, maize (Zea mays L.) was selected as the model plant for this study. Cr stress-induced phytotoxic lesions on maize plantlets have been described [14]. A previous proteomic study investigated proteome changes in chromium-treated maize plantlets, and identified 11 differently expressed proteins including some antioxidant enzymes, such as superoxide dismutase and 1-Cys peroxiredoxin [15]. However, as different tissues, such as leaf and root, respond differentially to environment stimuli [16], monitoring the molecular dynamics of maize leaf during $\mathrm{Cr}$ stress is probably one of the best approaches to deciphering the physiological mechanisms involved in the stress response.

To better understand the metabolic pathways implicated in the heavy metal stress response in maize, in the present study, the time-course of changes in soluble proteins elicited by short-term hexavalent chromium treatment in maize leaves were analyzed using a comparative proteomics approach. In total, 60 chromium stress-regulated proteins were determined and 58 of them were identified successfully by MS/MS analysis. The results not only identified a large number of differentially expressed proteins previously reported to be involved in the heavy metal stress response, but also revealed novel proteins that may play important roles in the Cr stress response.

\section{Results}

\subsection{The Morphological and Physiological Responses in Maize Leaves Induced by Cr Treatment}

Chromium accumulation in maize leaves increased with the duration of treatment (Figure 1). After 1 day of exposure to $300 \mathrm{mg} / \mathrm{L}$ potassium dichromate, the leaf tissue accumulated more than $12 \mathrm{mg} / \mathrm{kg}$ $\mathrm{Cr}$ on a dry weight basis, while that in the control plants was $<0.2 \mathrm{mg} / \mathrm{kg}$.

Figure 1. Effects of $\mathrm{Cr}$ treatment on $\mathrm{Cr}$ content of maize leaves. Maize seedlings were watered with $300 \mathrm{mg} / \mathrm{L}$ potassium dichromate solution for $24 \mathrm{~h}$ and the $\mathrm{Cr}$ concentrations of leaves were measured at the time point $0 \mathrm{~h}$ (prior to treatment), $1 \mathrm{~h}, 6 \mathrm{~h}$ and $24 \mathrm{~h}$. The $\mathrm{Cr}$ levels are mean values $\pm \mathrm{SE}$.

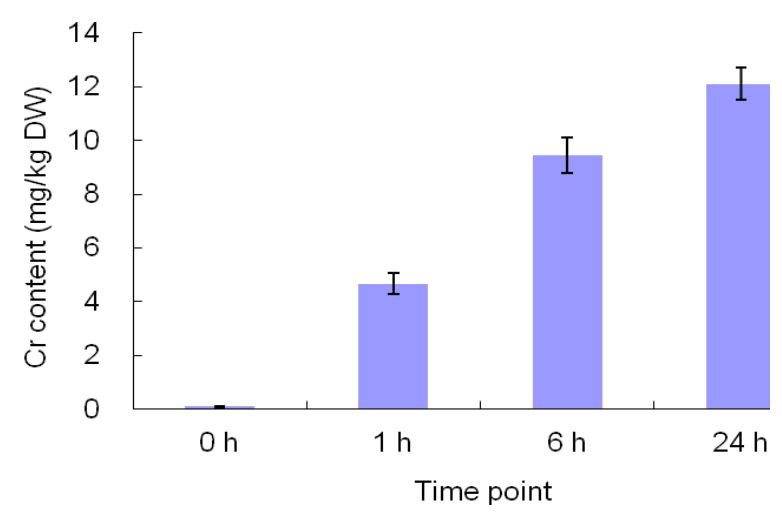

The exposure of maize seedlings to short-term $\mathrm{Cr}$ stress resulted in obvious changes in morphology (Figure 2). The margins of young and middle leaves (the second, third, and fourth leaves) curled inward after $6 \mathrm{~h}$ of $\mathrm{Cr}$ treatment (Figure 2). Significant wilting of leaves was observed after $12 \mathrm{~h}$ of $\mathrm{Cr}$ treatment (Figure 2), possibly resulting from $\mathrm{Cr}$ treatment-induced water stress. Similar Cr stress-induced 
symptoms were reported previously [14]. Relative electrolyte leakage (REL) is an indicator of membrane damage caused by environmental stress. To estimate the effects of $\mathrm{Cr}$ stress-induced membrane damage in maize leaves, REL was measured in plants after exposure to Cr stress for 1, 6, 12, or $24 \mathrm{~h}$. As shown in Figure 3a, the REL of maize leaves increased gradually, reaching a maximum at the 24-h time-point. Many types of environmental stress cause proline to accumulate to high levels in a number of plant species; thus, the proline content of Cr-stressed maize leaves was measured. The concentration of proline increased gradually with treatment duration, reaching a peak at the 24-h time-point (Figure 3b). Collectively, our results clearly demonstrated that the treatment regime used in this study increased the $\mathrm{Cr}$ concentration of maize leaves significantly, and caused marked damage to maize leaf cells.

Figure 2. Effects of Cr stress on maize morphology. Maize seedlings were watered with $300 \mathrm{mg} / \mathrm{L}$ potassium dichromate for $24 \mathrm{~h}$ and photographed at $0,1,6,12$, and $24 \mathrm{~h}$.

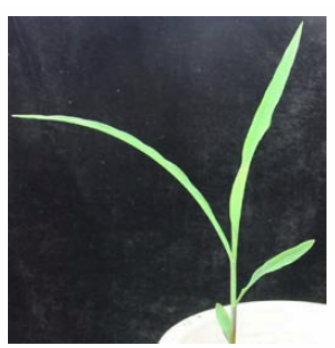

$\mathrm{Oh}$

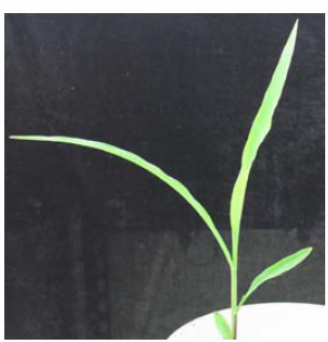

$1 \mathrm{~h}$

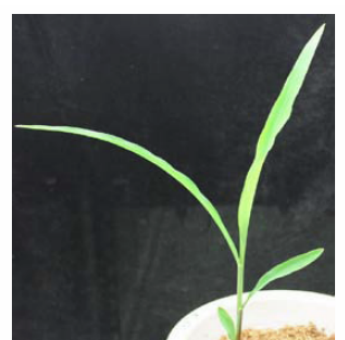

$6 \mathrm{~h}$

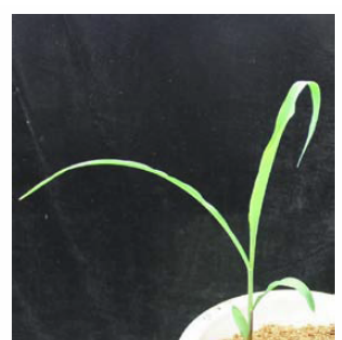

$12 \mathrm{~h}$

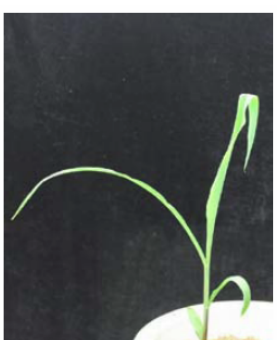

$24 \mathrm{~h}$

Figure 3. Physiological responses of maize leaves to $\mathrm{Cr}$ stress treatment. Maize seedlings were watered with $300 \mathrm{mg} / \mathrm{L}$ potassium dichromate for $24 \mathrm{~h}$ and the REL (a) and proline concentration (b) were measured at $0,1,6,12$, and $24 \mathrm{~h}$.

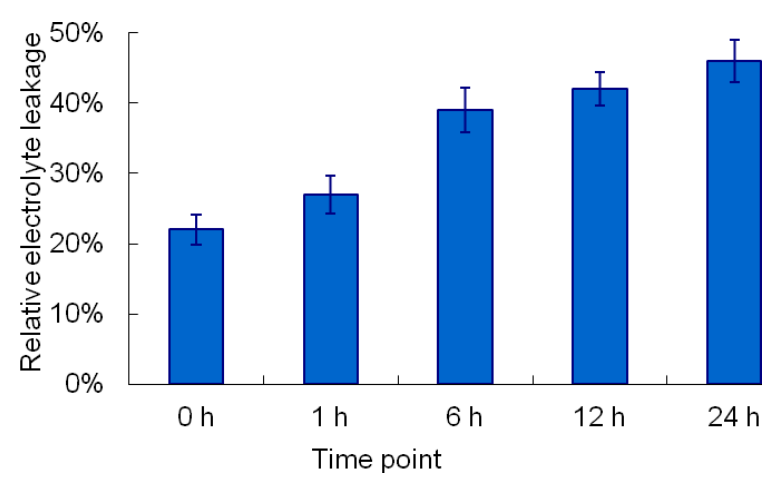

(a)

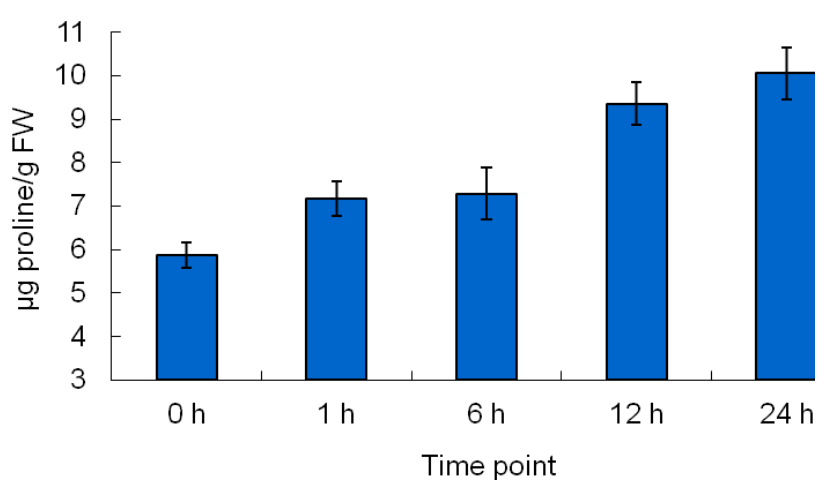

(b)

\subsection{2-DE Analysis of Cr-Treated Maize Leaf Proteins}

The morphological and physiological data showed that the leaves of plants treated with potassium dichromate for $24 \mathrm{~h}$ showed stress symptoms. To identify the protein targets of Cr toxicity in maize leaves, total leaf proteins were extracted from control and Cr-treated leaves and separated by 2-DE. To investigate the dynamic protein expression patterns in response to short-term $\mathrm{Cr}(\mathrm{VI})$ stress, proteomic alterations in maize leaves after $\mathrm{Cr}(\mathrm{VI})$ treatment for 1,6 , and $24 \mathrm{~h}$ were examined. Representative 2-DE gels of the soluble protein fractions of leaf samples are shown in Figure 4. To gain a better 
resolution of total leaf proteins, 24-cm dry strips with a $p I$ range of 4-7 were used. More than 1200 protein spots were reproducibly detected in each Coomassie brilliant blue (CBB)-stained gel using the ImageMaster Platinum 7.0 software. To evaluate the quantitative changes of each protein spot in the 2-DE gels, the relative spot volumes (\% vol) were used. By software analysis, Student's $t$-test $(p<0.05)$, coupled with a threshold of 1.5-fold change in abundance, revealed that 60 protein spots were differentially expressed in at least one time point during short-term potassium dichromate exposure (Figure $\mathrm{S} 1$ ).

Among the 60 differentially expressed protein spots, most showed quantitative changes; few spots (e.g., spots 1, 2, 50 and 54) either appeared or disappeared after $\mathrm{Cr}(\mathrm{VI})$ treatment. Of the $\mathrm{Cr}$ stress-responsive protein spots, five were identified at the 1-h time-point, 10 at the 6-h time-point, and 48 at the 24-h time-point (Figure 5). It is noteworthy that the majority of proteins (80\%) were upregulated after $\mathrm{Cr}$ treatment for $6 \mathrm{~h}$, while more proteins (61\%) were downregulated after $\mathrm{Cr}$ treatment for $24 \mathrm{~h}$.

Figure 4. Representative images of 2-DE gels. Total leaf proteins were extracted and separated by 2 -DE. Proteins $(1200 \mu \mathrm{g})$ were separated in the first dimension on immobilized $\mathrm{pH} 4-7 \mathrm{pH}$ dry strips (24 cm, linear) and in the second dimension on a $12.5 \%$ SDS-PAGE gel. The gel shown was stained with CBB-R250. Labeled spots indicate differentially expressed proteins showing at least a 1.5-fold change under $\mathrm{Cr}(\mathrm{VI})$ treatments, with $p<0.05$. (A) 2-DE gel of control ( $0 \mathrm{~h}$ ); (B) 2-DE gel of sample collected at the time-point $1 \mathrm{~h}$; (C) 2-DE gel of sample collected at the time-point $6 \mathrm{~h}$; (D) 2-DE gel of sample collected at the time-point $24 \mathrm{~h}$.
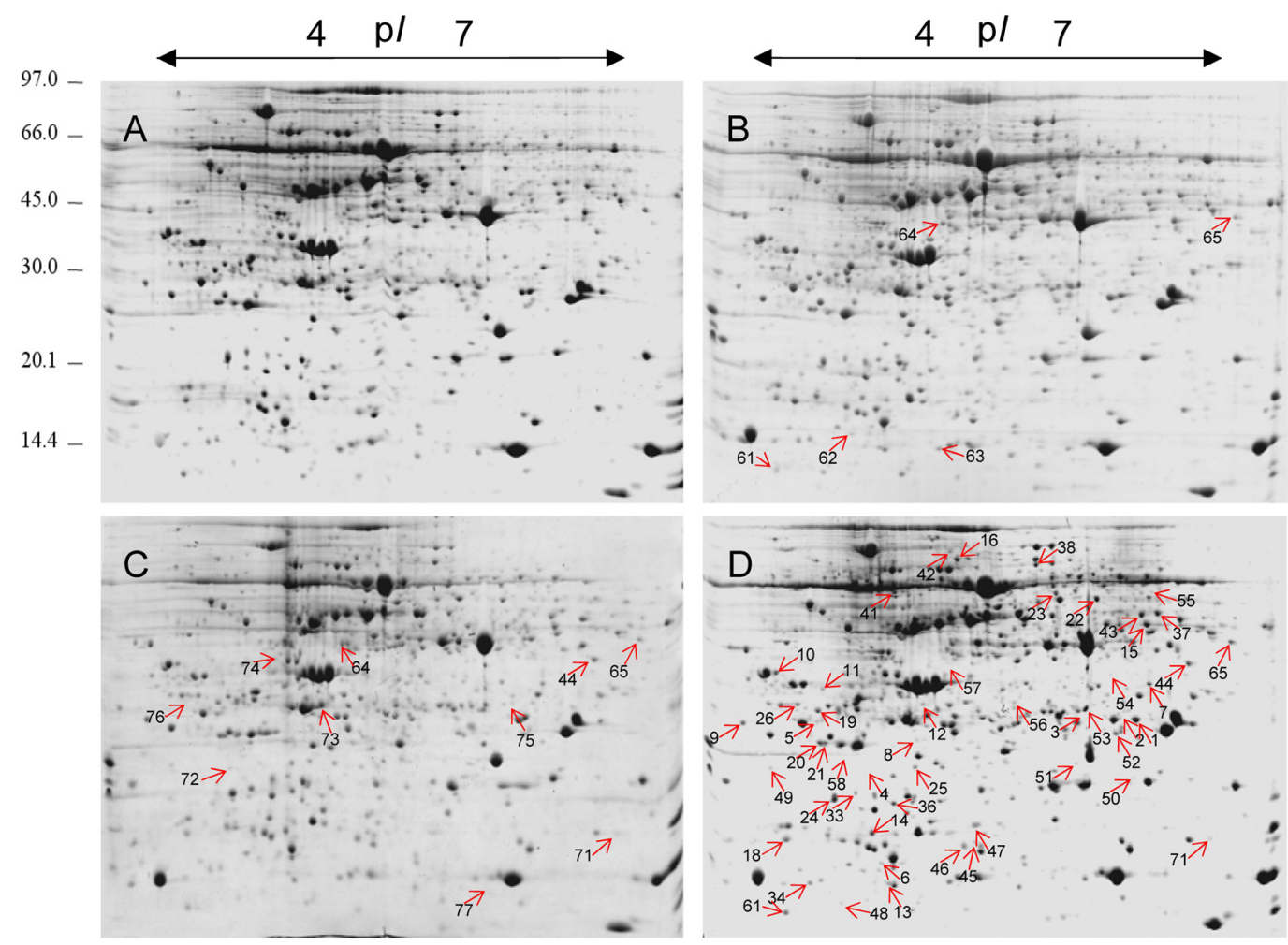
Figure 5. Distribution of protein spots upregulated, downregulated, and newly appearing or disappearing during $\mathrm{Cr}(\mathrm{VI})$ treatment.

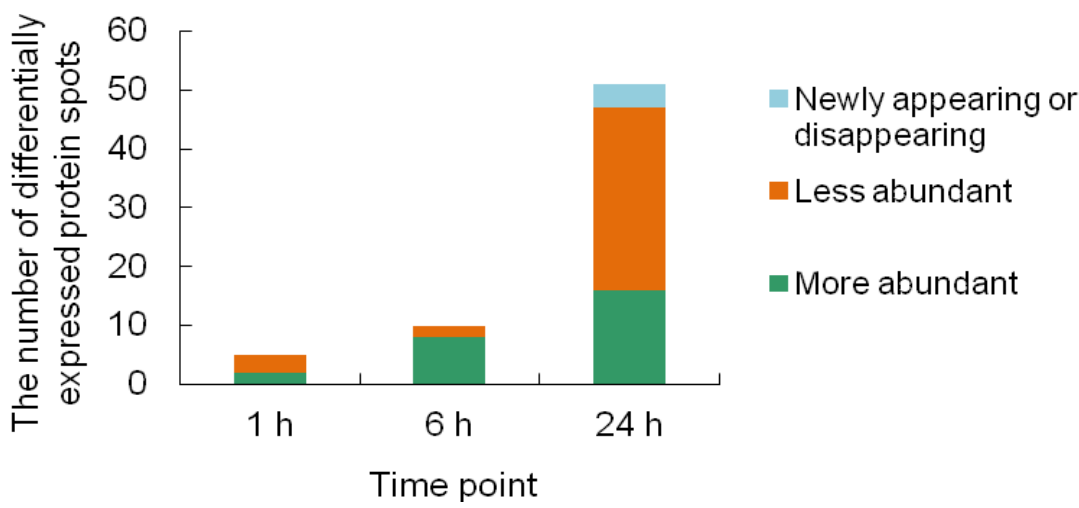

\subsection{Identification of the Differentially Expressed Proteins}

Of the 60 differentially expressed protein spots, 58 (96.7\%) were successfully identified using tandem mass spectrometry (MS/MS) and MASCOT searches, the abundance of two unidentified spots may have been too low for MS/MS analysis (Tables 1 and S1).

Table 1. Differentially expressed proteins under $\mathrm{Cr}$ stress conditions in maize leaves identified by MS analysis.

\begin{tabular}{|c|c|c|c|c|c|}
\hline $\begin{array}{l}\text { Spot } \\
\text { ID }\end{array}$ & $\begin{array}{l}\text { Accession } \\
\text { number }^{\text {a }}\end{array}$ & Protein name and plant species & Score & $\begin{array}{l}\text { Theor. } \\
\text { Mr/pI }\end{array}$ & $\begin{array}{c}\text { Exp. } \\
\text { Mr/pI }\end{array}$ \\
\hline \multicolumn{6}{|c|}{ Photosynthesis and chloroplast organization } \\
\hline 23 & gi|226508728 & uncharacterized protein LOC100275158 [Zea mays] & 414 & $51.9 / 6.12$ & $53 / 5.9$ \\
\hline 44 & gi|13096165 & $\begin{array}{c}\text { Chain A, Crystal Structure Of The Complex Between Ferredoxin } \\
\text { And Ferredoxin-Nadp }{ }^{+} \text {Reductase }[\text { Zea mays }]\end{array}$ & 263 & $35.6 / 7.01$ & $35 / 6.6$ \\
\hline 50 & gi|194697374 & unknown [Zea mays] & 337 & $23.1 / 9.07$ & $23 / 6.2$ \\
\hline 26 & gi|226503027 & uncharacterized protein LOC100272863 [Zea mays] & 148 & $28.9 / 4.85$ & $29 / 4.7$ \\
\hline 9 & gi|195613650 & ATP synthase delta chain $[$ Zea mays $]$ & 335 & $26.7 / 4.73$ & $27 / 4.2$ \\
\hline 46 & gi|77554379 & ATP synthase epsilon chain, putative [Oryza sativa] & 151 & $15.3 / 5.46$ & $16 / 5.4$ \\
\hline 38 & gi|30575690 & NADP-malic enzyme [Zea mays $]$ & 373 & $70.4 / 6.2$ & $70 / 5.8$ \\
\hline 73 & gi|1170606 & Adenylate kinase, chloroplastic [Zea mays] & 523 & $24.9 / 4.95$ & $25 / 5.2$ \\
\hline 16 & gi| 187830110 & filamentation temperature-sensitive $\mathrm{H}$ 2B [Zea mays] & 335 & $72.6 / 5.69$ & $73 / 5.4$ \\
\hline 7 & gi|195622012 & membrane-associated 30 kDa protein [Zea mays] & 344 & $35.1 / 9.5$ & $35 / 6.3$ \\
\hline 1 & gi|226497262 & ribosome recycling factor [Zea mays] & 373 & $29.3 / 9.22$ & $29 / 6.3$ \\
\hline 2 & gi|226497262 & ribosome recycling factor [Zea mays] & 373 & $29.3 / 9.22$ & $29 / 6.2$ \\
\hline 4 & gi|226508836 & uncharacterized protein LOC100277322 [Zea mays] & 131 & $23.4 / 6.31$ & $23 / 4.8$ \\
\hline \multicolumn{6}{|c|}{ Redox homeostasis and defense response } \\
\hline 53 & gi|226504576 & APx1-Cytosolic Ascorbate Peroxidase [Zea mays] & 764 & $27.5 / 5.65$ & $27 / 5.9$ \\
\hline 52 & gi|168624 & manganese superoxide dismutase (SOD-3) [Zea mays] & 407 & $25.6 / 7.11$ & $25 / 6.1$ \\
\hline 75 & gi|226530195 & uncharacterized protein LOC100272867 [Zea mays & 267 & $28.3 / 5.83$ & $28 / 6.2$ \\
\hline 55 & gi|194702230 & unknown $[$ Zea mays $]$ & 363 & $53.1 / 5.93$ & $53 / 6.2$ \\
\hline 12 & gi|414591366 & 6-phosphogluconolactonase isoform 1 [Zea mays] & 371 & $34.8 / 7.71$ & $31 / 5.2$ \\
\hline 21 & gi|195626524 & 2-cys peroxiredoxin BAS1 [Zea mays] & 81 & $28.3 / 5.81$ & $28 / 4.5$ \\
\hline
\end{tabular}


Table 1. Cont.

\begin{tabular}{|c|c|c|c|c|c|}
\hline $\begin{array}{l}\text { Spot } \\
\text { ID }\end{array}$ & $\begin{array}{l}\text { Accession } \\
\text { number }^{\text {a }}\end{array}$ & Protein name and plant species & Score & $\begin{array}{l}\text { Theor. } \\
\text { Mr/pI }^{\text {b }}\end{array}$ & $\begin{array}{c}\text { Exp. } \\
\text { Mr/pI }\end{array}$ \\
\hline \multicolumn{6}{|c|}{ Redox homeostasis and defense response } \\
\hline 20 & gi|195626524 & 2-cys peroxiredoxin BAS1 [Zea mays] & 89 & $28.3 / 5.81$ & $28 / 4.5$ \\
\hline 36 & gi|226505300 & LOC100283392 [Zea mays] & 165 & $17.3 / 4.85$ & $18 / 4.9$ \\
\hline 8 & gi|223943539 & unknown [Zea mays] & 309 & $28.1 / 8.79$ & $28 / 5.2$ \\
\hline 48 & gi|195624046 & thioredoxin X $[$ Zea mays $]$ & 213 & $19.3 / 8.75$ & $14 / 4.8$ \\
\hline 63 & gi|66866417 & cysteine proteinase inhibitor [Zea mays subsp. parviglumis] & 133 & $14.8 / 6.3$ & $15 / 5.4$ \\
\hline 56 & gi|293334301 & uncharacterized protein LOC100383635 [Zea mays] & 529 & $29.4 / 9.57$ & $28 / 5.6$ \\
\hline 22 & gi|226492878 & $\begin{array}{l}\text { bifunctional 3-phosphoadenosine 5-phosphosulfate synthetase } 2 \\
\text { [Zea mays] }\end{array}$ & 354 & $52.5 / 8.30$ & $52 / 6.2$ \\
\hline 37 & gi|226508814 & aspartate aminotransferase [Zea mays] & 306 & $50.5 / 8.15$ & $50 / 6.4$ \\
\hline 51 & gi|226532399 & peptide methionine sulfoxide reductase [Zea mays] & 775 & $20.8 / 5.85$ & $21 / 5.9$ \\
\hline \multicolumn{6}{|c|}{ RNA processing } \\
\hline 3 & gi|363543235 & uncharacterized protein LOC100857032 [Zea mays] & 421 & $23.9 / 5.95$ & $24 / 5.9$ \\
\hline 13 & gi|195642478 & glycine-rich RNA-binding protein 2 [Zea mays] & 115 & $15.6 / 9.00$ & $14 / 4.8$ \\
\hline 15 & gi|414884012 & hypothetical protein ZEAMMB73_274910 [Zea mays] & 253 & $42.3 / 8.14$ & $43 / 6.4$ \\
\hline 5 & gi| 226502782 & ribonucleoprotein A $[$ Zea mays $]$ & 123 & $28.5 / 4.83$ & $29 / 4.6$ \\
\hline 19 & gi|226502782 & ribonucleoprotein A [Zea mays] & 103 & $28.5 / 4.83$ & $30 / 4.5$ \\
\hline 10 & gi|162463757 & nucleic acid binding protein1 [Zea mays] & 274 & $33.2 / 4.6$ & $33 / 4.4$ \\
\hline 11 & gi|219363077 & uncharacterized protein LOC100217196 [Zea mays] & 284 & $31.5 / 5.13$ & $31 / 4.6$ \\
\hline \multicolumn{6}{|c|}{ Protein synthesis and folding } \\
\hline 1 & gi|413915954 & 40S ribosomal protein S16, mRNA [Zea mays] & 431 & $59.4 / 5.28$ & $53 / 5.1$ \\
\hline 47 & gi|195604208 & 40S ribosomal protein S12 [Zea mays] & 180 & $15.4 / 5.33$ & $18 / 5.4$ \\
\hline 61 & gi|195647902 & Glu-tRNAGIn amidotransferase, C subunit family [Zea mays] & 304 & $15.9 / 5.76$ & $14 / 4.6$ \\
\hline 6 & gi|414585580 & CHL-CPN10 $[$ Zea mays $]$ & 106 & $14.5 / 6.15$ & $15 / 4.8$ \\
\hline 33 & gi|195610950 & 50S ribosomal protein L12-1 [Zea mays] & 147 & $19.1 / 5.4$ & $19 / 4.9$ \\
\hline 24 & gi|195659273 & 50S ribosomal protein L12-1 [Zea mays] & 156 & $19.0 / 5.71$ & $19 / 4.7$ \\
\hline \multicolumn{6}{|c|}{ DNA damage response } \\
\hline 71 & gi|414881042 & putative ubiquitin-conjugating enzyme family [Zea mays] & 377 & $17.3 / 6.74$ & $17 / 6.7$ \\
\hline 64 & gi|239985534 & thiamine thiazole synthase 2 , chloroplastic precursor [Zea mays] & 432 & $37.4 / 5.59$ & $38 / 5.3$ \\
\hline 57 & gi|239985530 & thiamine thiazole synthase 1 , chloroplastic precursor [Zea mays] & 279 & $37.3 / 4.87$ & $34 / 5.3$ \\
\hline \multicolumn{6}{|c|}{\begin{tabular}{|c|} 
Cytoskeleton \\
\end{tabular}} \\
\hline 34 & gi|162461296 & profilin-5 [Zea mays $]$ & 177 & $14.2 / 4.59$ & $14 / 4.6$ \\
\hline 45 & gi|162459533 & actin-depolymerizing factor 3 [Zea mays] & 490 & $16.0 / 5.46$ & $16 / 5.4$ \\
\hline \multicolumn{6}{|c|}{ Mitochondrial oxidative phosphorylation } \\
\hline 25 & gi|226507194 & ATP synthase D chain, mitochondrial [Zea mays] & 178 & $19.9 / 5.19$ & $23 / 5.2$ \\
\hline 72 & gi|223973939 & unknown $[$ Zea mays $]$ & 246 & $24.3 / 5.68$ & $24 / 4.8$ \\
\hline \multicolumn{6}{|c|}{ Miscellaneous and unknown } \\
\hline 42 & gi|414882068 & putative alpha-L-arabinofuranosidase family protein [Zea mays $]$ & 303 & $73.0 / 5.1$ & $73 / 5.2$ \\
\hline 76 & gi|195638660 & heme-binding protein $2[$ Zea mays $]$ & 448 & $23.8 / 4.75$ & $24 / 4.5$ \\
\hline 54 & gi|226532343 & SOUL heme-binding protein [Zea mays] & 529 & $32.1 / 9.09$ & $33 / 6.2$ \\
\hline 65 & gi|226507242 & uncharacterized protein LOC100274379 [Zea mays] & 776 & $38.8 / 6.3$ & $38 / 6.7$ \\
\hline 18 & gi|226493727 & uncharacterized protein LOC100275650 [Zea mays] & 107 & $17.6 / 5.79$ & $16 / 4.4$ \\
\hline
\end{tabular}


Table 1. Cont.

\begin{tabular}{|c|c|c|c|c|c|}
\hline $\begin{array}{l}\text { Spot } \\
\text { ID }\end{array}$ & $\begin{array}{l}\text { Accession } \\
\text { number }^{\text {a }}\end{array}$ & Protein name and plant species & Score & $\begin{array}{l}\text { Theor. } \\
\text { Mr/pI }^{\text {b }}\end{array}$ & $\begin{array}{r}\text { Exp. } \\
\text { Mr/pI }\end{array}$ \\
\hline \multicolumn{6}{|c|}{ Miscellaneous and unknown } \\
\hline 14 & gi|302819846 & $\begin{array}{l}\text { Hypothetical protein SELMODRAFT_133757 } \\
\text { [Selaginella moellendorffii }]\end{array}$ & 131 & $17.2 / 5.22$ & $16 / 4.8$ \\
\hline 49 & gi|226508942 & Uncharacterized protein LOC100275367 [Zea mays] & 88 & $23.4 / 4.97$ & $23 / 4.4$ \\
\hline 58 & gi|226528599 & Uncharacterized protein LOC100276423 [Zea mays] & 215 & $19.8 / 4.71$ & $23 / 4.9$ \\
\hline 74 & gi|195635483 & Membrane steroid-binding protein 1 [Zea mays] & 425 & $27.9 / 5.45$ & $28 / 5.0$ \\
\hline 62 & gi|223948417 & Unknown [Zea mays] & 115 & $20.4 / 7.66$ & $15 / 4.8$ \\
\hline
\end{tabular}

${ }^{\mathrm{a}}$ Accession number in the NCBI nr (green plants) database; ${ }^{\mathrm{b}}$ Theoretical molecular weight and isoelectric point; ${ }^{\mathrm{c}}$ Experimental molecular weight and isoelectric point.

Some of the proteins identified were annotated as unknown and uncharacterized protein or as proteins without a specific function in the NCBI nr (green plants) database. To gain more information about functions and subcellular locations of these proteins, we searched them against known homologues in UniProtKB [17] and TAIR10 [18] with the BLASTP algorithm [19] using their amino acid sequences as queries. Homologues with the highest identity are shown in Table S1. All homologues in UniProtKB shared $100 \%$ positives with the corresponding proteins at the amino acid level, indicating that they are the same protein.

The 58 identified proteins spots were divided into eight groups according to their biological processes in UniProtKB [17] (Figure 6). The largest group was related to ROS detoxification and defense response (26\%), including $15 \mathrm{Cr}$ stress-responsive protein spots (spots 4, 8, 12, 20, 21, 22, 36, $37,48,51,52,53,55,56,63$, and 75 , representing 14 unique proteins). The second-largest group contained 13 proteins (22\%) associated with photosynthesis and chloroplast organization (spots 1, 2, 4, $7,9,16,23,26,38,44,46,50$, and 73$)$. The third group included seven proteins (12\%) involved in post-transcriptional processing of mRNA and rRNA (spots 3, 5, 10,11, 13, 15, and 19). The fourth group consisted of six proteins (10\%) related to protein synthesis and folding (spots 6, 24, 41, 33, 47, and 61). The fifth group included three proteins (5\%) associated with DNA damage response (spots 57, 64, and 71). The remaining three protein groups were involved in mitochondrial oxidative phosphorylation (spots 25 and 72), cytoskeleton (spots 34 and 45), and miscellaneous and unknown (spots 14, 18, 42, 49, 54, 58, 62, 65, 74, and 76).

Many $\mathrm{Cr}$ stress-responsive proteins identified in our experiments have already been discussed in the context of abiotic-stress responses. These include phosphomannomutase (spot 75) [20], 6-phosphogluconate dehydrogenase family protein (spot 55) [21], ATP sulfurylase (spot 22) [22], aspartate aminotransferase (spot 37) [23], peptide methionine sulfoxide reductase (spot 51) [24], 2-cys peroxiredoxin BAS1 (spots 20 and 21) [22], thioredoxin-dependent peroxidase 1 (TPX1) (spot 36) [25], thioredoxin X (spot 48) [25], cysteine proteinase inhibitor (spot 63) [22], glycine rich protein 2 (GRP2) (spots 3 and 13) [26], ubiquitin-conjugating enzyme E2 (UBC13B) (spot 71) [27], actin-depolymerizing factor 3 (ADF3) (spot 45) [28], filamentation temperature-sensitive H 2B (spot 16) [29], chloroplastic adenylate kinase (spot 73) [15], cytosolic ascorbate peroxidase (spot 53) [30], manganese superoxide dismutase (spot 52) [15], and chloroplastic thiamine thiazole synthase 1 and 2 (spots 57 and 64) [31]. Some proteins not previously reported to be involved in plant responses to abiotic-stress were 
identified, such as ribosome recycling factor (spots 1 and 2), glutamyl-tRNA(Gln) amidotransferase subunit C, chloroplastic/mitochondrial (spot 61), membrane steroid-binding protein 1 (spot 74), and profilin-5 (spot 34). Our results validate the efficacy of proteomics technologies or the identification and characterization of proteins involved in plant $\mathrm{Cr}$ stress responses.

Figure 6. Functional distribution of 58 proteins differentially expressed in maize leaves under chromium stress. In total, eight functional groups are shown.

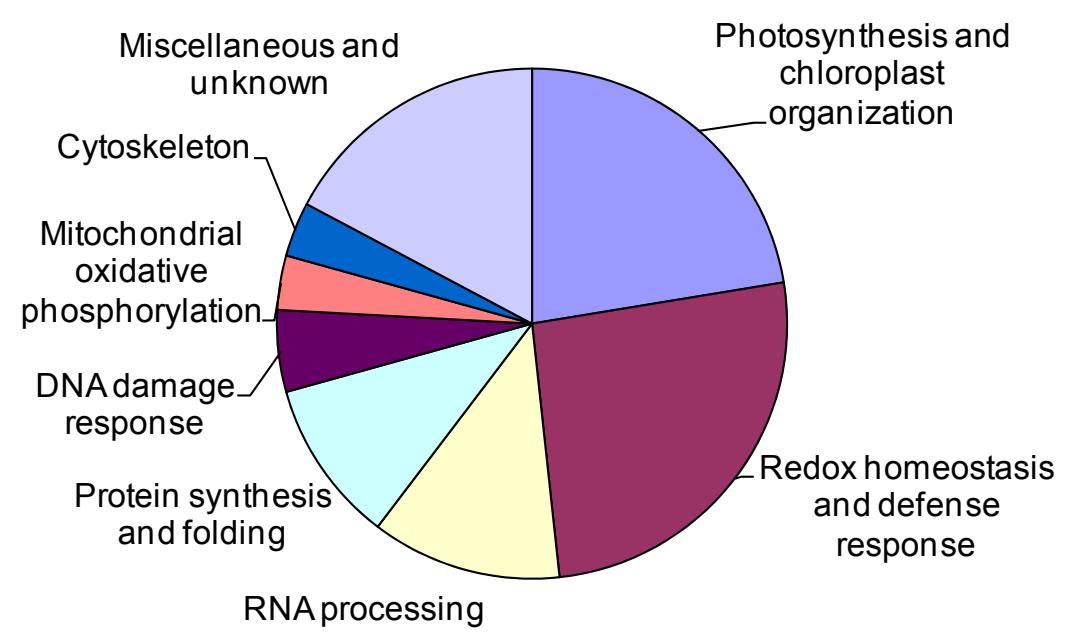

\section{Discussion}

\subsection{Photosynthesis and Chloroplast Organization}

Photosynthesis is the most fundamental biological process in leaves. Previous studies revealed that chromium stress negatively affects chloroplast function, with toxic effects of: electron transport inhibition, reduced chlorophyll, calvin cycle enzyme inactivation, reduced $\mathrm{CO}_{2}$ fixation and chloroplast disorganization [9,14,32]. Not surprisingly, a large proportion $(72 \%, 42 / 58)$ of the identified Cr-stress responsive proteins was predicted to be localized to the chloroplast in UniProtKB [17] (Table S1). These chloroplast-located $\mathrm{Cr}$ stress-responsive proteins are associated with various aspects of chloroplast structure and function, including proteins involved in photosynthetic electron transport, chloroplast organization and chlorophyll biosynthesis, and chloroplast redox homeostasis (thioredoxin X, 2-cys peroxiredoxin BAS1 and peptide methionine sulfoxide reductase), chloroplast RNA processing (ribonucleoprotein A), and chloroplast protein synthesis and folding (50S ribosomal protein L12-1 and CHL-CPN10). This result suggests that the regulation of chloroplast function is a central part of chromium stress responses in maize leaves.

It is well established Cr stress impairs electron transport [9]. In the present study, two subunits of ATP synthase (spot 9, ATP synthase delta chain; spot 46, ATP synthase epsilon chain, putative) were downregulated, possibly resulting in destabilization of the ATP synthase complex and a reduction of photophosphorylation.

The electron transport inhibition and chloroplast disorganization induced by $\mathrm{Cr}$ stress may result in photosynthetic apparatus damage, such as photosystem II (PSII) photodamage and chloroplast swelling. In this study, the up-regulation of a filamentation temperature-sensitive H $2 \mathrm{~B}$ (spot 16) and a VIPP1 homologue (spot 7) under Cr stress may help to alleviate chloroplast structural damage. 
Filamentation temperature-sensitive $\mathrm{H} \mathrm{2B}$ (spot 16) is a metalloprotease that functions in thylakoid membrane biogenesis, and a recent report showed that the protein participates in repair of PSII following damaged incurred during photoinhibition [29]. The homologue of spot 7 in Arabidopsis, VIPP1 (a protein encoded by AT1G65260.1), is essential for thylakoid membrane formation, which was recently demonstrated to play a protective role in chloroplast envelope maintenance under stress condition [33].

Adenylate kinases equilibrate adenylates by the reversible formation of ADP through transfer of one phosphate group from ATP to AMP. The chloroplastic adenylate kinase is thought to play a vital role in the equilibration of adenylates and de novo synthesis of ADP in chloroplast, and the absence of AMK2 causes loss of chloroplast integrity [34]. The upregulation of chloroplastic adenylate kinase (spot 73) in this study may provide more adenylate substrate for ATP synthesis in stressed chloroplasts. Although upregulation of adenylate kinase induced by $\mathrm{Cr}$ stress of $72 \mathrm{~h}$ in maize plantlets had been reported previously [15], and adenylate kinase has been observed to be induced by drought stress in tomato [35], the relationship between adenylate kinase and environmental stress in plants remains unclear.

A ribosome recycling factor spot (spot 2), identified from 2-DE gels of control samples, was absent from 2-DE gels of 24-h Cr-treated samples, while a neighboring ribosome recycling factor spot (spot 1) with a similar molecular weight and a little higher isoelectric point emerged in gels of the 24-h Cr-treated samples, suggesting a possible post-translational modification of this protein induced by $\mathrm{Cr}$ stress. Because Arabidopsis chloroplast ribosome recycling factor was shown to play a critical role in chloroplast biogenesis [36], the changes in this protein observed here suggest that chloroplast ribosome recycling factor may be involved in chloroplast structure maintenance under Cr stress.

\subsection{Defense Response and ROS Detoxification}

Cr stress disturbs cellular redox homeostasis and promotes the production of reactive oxygen species (ROS), and plants activate ROS scavenging mechanisms to cope with oxidative stress [9]. Several proteins involved in cytosolic and chloroplast redox homeostasis were found to be regulated in the present study; this result is consistent with two previous Cr stress response studies [13,15].

Previous studies revealed that $\mathrm{Cr}$ stress promotes ROS accumulation partly by negatively affecting the electron transfer chains of the chloroplasts and mitochondria [37,38], yet the toxic effects at the molecular level remain incompletely understood. In the present study, several components of the electron transfer chains of the chloroplasts (discussed above) and mitochondria were found to be regulated by $\mathrm{Cr}$ stress, advancing our understanding of $\mathrm{Cr}$ toxicity to cellular redox homeostasis. Two proteins involved in the electron transfer chains of the mitochondria were identified: a mitochondrial ATP synthase D chain (spot 25), the abundance of which is downregulated, and a homologue of Arabidopsis NADH-ubiquinone oxidoreductase-related protein, which was upregulated by $\mathrm{Cr}$ stress. Additionally, apart from ROS generated by chloroplasts, mitochondria and peroxisomes, free radicals will be produced intracellularly during the reduction of $\mathrm{Cr}(\mathrm{VI})$ to $\mathrm{Cr}(\mathrm{III})$ [9]. All excess ROS must be eliminated by the cellular ROS detoxification systems.

Because of its inability to penetrate the membrane, $\mathrm{O}_{2}{ }^{-}$produced in the mitochondrial electron transfer chains is converted to $\mathrm{H}_{2} \mathrm{O}_{2}$. The reaction is catalyzed by superoxide dismutases (SOD). SOD 
catalyzes the breakdown of superoxide radicals, $\mathrm{O}_{2}^{-}$, and constitutes the first line of defense against ROS toxicity. In the present study, a mitochondrial manganese superoxide dismutase (SOD-3) was upregulated under Cr stress, suggesting an important role of SOD-3 in redox homeostasis control in maize leaf cells.

$\mathrm{H}_{2} \mathrm{O}_{2}$ is the most stable ROS molecule in cells, and the major sources of $\mathrm{H}_{2} \mathrm{O}_{2}$ include the electron transfer chains of the chloroplasts and mitochondria, as well as peroxisomes. Due to its ability to penetrate membranes freely, $\mathrm{H}_{2} \mathrm{O}_{2}$ is believed to be an ideal candidate for ROS signaling. Ascorbate peroxidase (APX) is the key $\mathrm{H}_{2} \mathrm{O}_{2}$ scavenging enzyme, other than catalase, which only catalyzes higher concentrations of $\mathrm{H}_{2} \mathrm{O}_{2}$. In our study, APX1 (spot 53) showed enhanced expression under $\mathrm{Cr}$ stress. Despite its cytoplasmic localization, APX1 has been suggested to play an important role in protecting chloroplasts against ROS [39].

The enhanced catalysis of $\mathrm{H}_{2} \mathrm{O}_{2}$ by APX1 may need higher levels of ascorbic acid (AsA). In the biosynthetic pathway for AsA in higher plants, phosphomannomutase (PMM) catalyzes the interconversion of mannose 6-phosphate and mannose 1-phosphate, and is involved in AsA biosynthesis and $N$-glycosylation [20,40]. Our results revealed that a homologue of Arabidopsis PMM (AT2G45790) showed elevated accumulation, indicating enhanced AsA synthesis in response to Cr stress.

In the ascorbate-glutathione pathway, glutathione $(\mathrm{GSH})$ regenerates ascorbate by reducing dehydroascorbate (DHA). A protein (spot 22) that influences GSH level was upregulated in the present study, suggesting that more $\mathrm{GSH}$ is needed to diminish the elevated $\mathrm{H}_{2} \mathrm{O}_{2}$ via the ascorbate-glutathione pathway. Spot 22 is identified as bifunctional 3-phosphoadenosine 5-phosphosulfate synthetase 2 (ATP sulfurylase), which is the first enzyme in the sulfate assimilation pathway in plants. The enhanced expression of ATP sulfurylase under $\mathrm{Cr}$ stress may provide more GSH for ascorbate regeneration. More NADPH is required for the reduction of glutathione disulfide (GSSG) to GSH via glutathione reductase in plants under stress. A previous study suggested that the pentose phosphate pathway (PPP) plays an important role in plant responses to abiotic stresses; indeed, the second key enzyme of the PPP, 6-phosphogluconate dehydrogenase (6PGDH), may function as a regulator, controlling the efficiency of the PPP under abiotic stresses [21]. In the present study, we found a 6PGDH (spot 55) showing enhanced expression under $\mathrm{Cr}$ stress, indicating that PPP was enhanced under $\mathrm{Cr}$ stress. The enhanced PPP may provide more NADPH for GSH regeneration. We also found a 6-phosphogluconolactonase (PGL, spot 12), which was downregulated under Cr stress. Knockdown of PGL3, a 6-phosphogluconolactonase in Arabidopsis, leads to a significant increase in total glucose-6-phosphate dehydrogenase (G6PDH, the rate-limiting enzyme of the PPP) activity, resulting in a significantly higher total GSH level and the GSH/GSSG ratio [41]. Thus, downregulation of PGL in Cr-stressed maize leaves may enhance NADPH supply via promoting G6PDH activity.

Elevated ROS cause methionine (Met) oxidation to methionine sulfoxide (MetSO), which results in the modification of the activity and conformation of many proteins, and methionine sulfoxide reductase (MSR) catalyzes the reduction of MetSO back to Met. In the present study, a chloroplast MSR (spot 51) was upregulated by Cr stress, indicating involvement in the protection of chloroplasts against oxidative damage. Our result is consistent with a previous report that MSRs respond to drought, cold, and high light stress [24].

We also found two plant defense-related proteins (spot 63, cysteine protease inhibitor; spot 56, harpin binding protein 1) to be involved in $\mathrm{Cr}$ stress responses. Among them, cysteine protease 
inhibitors are involved in the regulation of protein turnover and play an important role in resistance against insects and pathogens [42], as well as tolerance to salt, drought, and cold stress [43]. Harpin binding protein induces plants to generate systemic acquired resistance (SAR) and has great biological significance in pest control [44].

\subsection{Post-Transcriptional Processing of RNA}

Recent advances in proteomics and metabolic profiling have suggested that, apart from the transcriptional regulation, post-transcriptional regulatory mechanisms also play key roles in plant abiotic stress responses [45]. RNA binding proteins bind RNA molecules immediately after transcription, forming mRNP complexes until completion of translation, participating in various steps of RNA processing and affecting the RNA population both quantitatively and qualitatively [46]. Our findings revealed that seven RNA binding proteins possibly involved in mRNA and rRNA processing were regulated by $\mathrm{Cr}$ stress, with six downregulated and one upregulated. Thus post-transcriptional processing of RNA in maize leaves may be impaired under elevated chromium conditions.

Among the various RNA-binding proteins, the glycine-rich RNA-binding proteins (GRPs) have been demonstrated to be involved in plant responses to a variety of environmental stresses, including heavy metals, cold, and drought stress [26]. A GRP1A and a GRP7 were found to be upregulated under cold stress [22], but downregulated in salt stress in Thellungiella salsuginea [47]; Arabidopsis GRP2, GRP4, and GRP7 affect seed germination, seedling growth, and stress tolerance of Arabidopsis plants under cold, salt, and dehydration stress conditions [48-50], and GRP7 has been shown to confer freezing tolerance by acting as a RNA chaperone in regulating export of mRNA [49]. In this study, two glycine-rich RNA-binding proteins (spots 3 and 13) were downregulated by $\mathrm{Cr}$ stress, indicating for the first time that $\mathrm{Cr}$ stress may negatively affect post-transcriptional processing of mRNA and rRNA. Additionally, Cr stress induces downregulation of GRP7 and ribonucleoprotein A, two proteins closely related to innate immune responses in plants [51], indicating that $\mathrm{Cr}$ stress may impair plant defense system.

\subsection{Protein Synthesis and Folding}

Heavy metal stress, or the oxidative stress induced by heavy metals, may affect protein synthesis apparatus, directly or indirectly [52]. Large quantities of misfolded proteins may accumulate in cells under stress conditions; higher levels of protein chaperones are needed to refold these proteins. In this study, six Cr-stress responsive protein spots, representing five proteins involving in protein synthesis and folding, were identified, including three ribosomal proteins (spots 24 and 33, chloroplast 50S ribosomal protein L12-1; spot 47, cytosolic 40S ribosomal protein S12), a protein involved in regulation of the translational fidelity (spot 61, Glu-tRNAGln amidotransferase, C subunit family protein), and two proteins participating in protein folding (spot 6, CHL-CPN10; spot 41, 40S ribosomal protein S16). Of the six protein spots, five were down-regulated and only one, spot 41, was upregulated. Our result is consistent with a previous study in which $\mathrm{Cr}$ stress induces upregulation of a proteins chaperone in Miscanthus sinensis [13]. These findings demonstrated involvement of regulation of protein translation and folding in the chromium stress response in maize leaves. 


\subsection{DNA Damage Response}

Cr-induced DNA damage is thought to be caused directly by interactions between chromium and DNA [53], or indirectly, by $\mathrm{Cr}(\mathrm{VI})$-induced oxidative stress (i.e., the elevated intracellular ROS concentration [54]), although the evidence is mainly from mammalian cells. In this study, three proteins that are likely related to DNA damage responses were regulated under $\mathrm{Cr}$ stress: putative ubiquitin-conjugating enzyme family (spot 71), thiamine thiazole synthase 2 (chloroplastic precursor) (spot 64), and thiamine thiazole synthase 1 (chloroplastic precursor) (spot 57), suggesting that the elevated $\mathrm{Cr}$ concentration induced DNA damage in maize leaves. A homologue of the putative ubiquitin-conjugating enzyme family (Zea mays) in Arabidopsis thaliana (identity = 98\%), UBC36/UBC13B, encodes a protein that may play a role in DNA damage responses and error-free post-replicative DNA repair [27]. The homologues of the other two thiamine thiazole synthase chloroplastic precursors (Zea mays) in Arabidopsis thaliana (identities $=78 \%$ and $74 \%$, respectively) may play important roles in adaptation to various stress conditions and in DNA damage tolerance [55]. This finding demonstrates for the first time the potential genotoxicity of $\mathrm{Cr}(\mathrm{VI})$ in plant cells.

\subsection{Cytoskeleton}

The actin cytoskeleton is critical for a variety of cellular processes. Two actin-cytoskeletonorganization-related proteins were downregulated under $\mathrm{Cr}$ stress: an actin-depolymerizing factor 3 (ADF3, spot 45) and a profilin-5 (spot 34). ADF3 has been reported to be responsive to various environmental stresses, such as salt, oxidative, and cadmium stress, in Arabidopsis [28,56]. Maize ADF3 localizes to a region where actin is being remodeled during tip growth [57], suggesting ADF3 may play a role in plant growth. Profilin binds to actin and affects the structure of the cytoskeleton in a concentration-dependent manner. At high concentrations, profilin prevents the polymerization of actin whereas at low concentrations, it enhances the polymerization. Arabidopsis PRF3 (formerly profilin-5, homologue of maize profilin-5) is strongly expressed in young seedlings and affects cell elongation and F-actin organization [58]. The downregulation of ADF3 and profilin-5 in maize leaves observed in this study is closely related to the growth inhibition induced by $\mathrm{Cr}$ stress reported previously [9].

\subsection{Miscellaneous and Unknown Proteins}

SOUL heme-binding protein is thought to function in heme transfer or heme binding to prevent damage by ROS [59]. A SOUL heme-binding protein (spot 54) and a heme-binding protein 2 (spot 76, a homologue of Arabidopsis SOUL heme-binding family) were found to be upregulated under $\mathrm{Cr}$ stress, suggesting their involvement in ROS detoxification. A membrane steroid-binding protein 1 (MSBP1, spot 74) showed decreased abundance under Cr stress. MSBP1 is believed to act as a negative factor at an early stage of brassinosteroids (BRs) synthesis [60]. Because BRs promote tolerance in plants to a wide range of stresses, including heat, cold, drought, and salinity [61], the downregulation of MSBP1 may lead to activation of the BR signaling pathway, leading to enhanced tolerance to $\mathrm{Cr}$ stress. Our results suggest for the first time that BR signaling may be involved in $\mathrm{Cr}$ stress response. Additionally, a mitochondrial ATP synthase D chain (spot 25) was downregulated and 
another component of the respiratory electron transport chain (spot 72) was upregulated, suggesting that $\mathrm{Cr}$ stress had a toxic effect on mitochondrial oxidative phosphorylation.

As a starting point to address the molecular mechanisms underlying the $\mathrm{Cr}$ stress induced physiological response in maize leaves, the present study identified $\mathrm{Cr}$ stress-responsive proteins, providing important data for understanding the $\mathrm{Cr}$ stress-induced response in maize leaves. However, a maize leaf consists of cells of various developmental stages, which exhibit differing metabolic activities, which may lead to accumulation of different amounts of Cr. Future studies should focus on the growth zone of the leaf, because cell production and expansion are restricted to that segment, to decipher the mechanism behind the Cr-induced leaf growth reduction. It is also noteworthy that the photosynthetic apparatus in $\mathrm{C} 4$ plants, including maize, is partitioned into two cell types, called the mesophyll (M) and bundle sheath (BS) cells, the differentiation of the specialized M and BS cells was recently achieved by a combination of microscopy and quantitative proteomics [62]. Investigation of the $\mathrm{M}$ - and BS-specific Cr-stress responses will provide deeper insight into C4-cell-specific adaptation mechanisms to environmental factors.

\section{Experimental Section}

\subsection{Plant Growth and Chromium Treatment}

Maize (Zea mays L.) seeds of the Zheng 58 inbred line were germinated in the dark at $25{ }^{\circ} \mathrm{C}$ on blotting paper saturated with deionized water. After $72 \mathrm{~h}$, seedlings were transferred to 1-L pots filled with vermiculite, and placed in a growth chamber with a day/night regime of $16 / 8 \mathrm{~h}$ and a light intensity of $180 \mu \mathrm{mol} \mathrm{m} \mathrm{m}^{-2} \mathrm{~s}^{-1}$ at plant level, with a temperature of $22-24{ }^{\circ} \mathrm{C}$ in the dark and $25-27{ }^{\circ} \mathrm{C}$ in the light, with a relative humidity of $50 \%$. Seedlings were watered every 4 days with half-strength Hoagland nutrient solution.

After the fourth leaves were fully developed, the plantlets were divided into four groups randomly, and three were watered with $300 \mathrm{mg} / \mathrm{L}$ potassium dichromate. The second and third leaves were excised from the seedlings after 1, 6 and $24 \mathrm{~h}$, and the corresponding leaves separated from the untreated seedling were used as the control $(0 \mathrm{~h})$. All the leaf samples were snap-frozen in liquid nitrogen and stored at $-80{ }^{\circ} \mathrm{C}$.

\subsection{Determination of $\mathrm{Cr}$ Accumulation}

After treatment, leaf samples were washed with deionized water to remove surface $\mathrm{Cr}$ salts. The samples were dried in an incubator at $80{ }^{\circ} \mathrm{C}$ for $24 \mathrm{~h}$, weighed, and then ground to a fine powder. Approximately $0.5 \mathrm{~g}$ of fine powder from each treatment group was digested, using a ternary solution $\left(\mathrm{HNO}_{3} / \mathrm{H}_{2} \mathrm{SO}_{4} / \mathrm{HClO}_{4}, 10: 1: 4 \mathrm{v} / \mathrm{v}\right)$, and the total $\mathrm{Cr}$ in the digestion solution was determined with an atomic absorption spectrophotometer (Solaar M6, Thermo Fisher Scientific, Waltham, MA, USA). Three different biological replicate root samples were subjected to analysis.

\subsection{Physiological Parameter Measurement}

The relative electrolyte leakage (REL) assay was performed according to a method described previously [63]. Proline was determined according to Bates et al. [64]. Briefly, $0.5 \mathrm{~g}$ fresh weight of 
leaves was homogenized with $5 \mathrm{~mL}$ of $3 \%$ sulfosalicylic acid, and the homogenate was cooled after heating for $10 \mathrm{~min}$ at $100{ }^{\circ} \mathrm{C}$. After centrifugation $(4000 \times \mathrm{g}, 10 \mathrm{~min})$, the content of free proline in the supernatant was measured using Ninhydrin reagent at $520 \mathrm{~nm}$ and expressed as $\mu \mathrm{g} \mathrm{g}^{-1}$ fresh weight. Eight replicates were performed for each sample.

\subsection{Protein Extraction and Two-Dimensional Electrophoresis}

The leaf proteins were extracted using a trichloroacetic acid/acetone method as described previously [22]. Protein concentration was determined using the Bradford assay (Bioteke, Beijing, China). For 2-DE, $1200 \mu \mathrm{g}$ of extracted proteins were loaded onto semi-preparative gels. For isoelectric focusing, the Ettan IPGphor 3 isoelectric focusing system (GE Healthcare, Piscataway, NJ, USA) and $\mathrm{pH}$ 4-7 IPG strips (24 cm, linear) were used according to the manufacturer's recommendations. The IPG strips were rehydrated for $13 \mathrm{~h}$ in $450 \mu \mathrm{L}$ rehydration buffer containing protein samples. The gel strips were equilibrated for $15 \mathrm{~min}$ in $10 \mathrm{~mL}$ equilibration buffer $(50 \mathrm{mM}$ Tris-HCl buffer, $\mathrm{pH} 8.8,6 \mathrm{M}$ urea, 30\% $v / v$ glycerol, 2\% $w / v$ SDS, $1 \% w / v$ DTT and $0.002 \% w / v$ bromophenol blue). SDS-PAGE was performed with $12.5 \%$ gels using the Ettan Six system (GE Healthcare, Piscataway, NJ, USA). The gels were run at $5 \mathrm{~W}$ per gel for the first $30 \mathrm{~min}$, followed by $17 \mathrm{~W}$ per gel.

Proteins in 2-DE gels were visualized by CBB R-250. The gels were scanned (400 dpi, 16-bit gray-scale pixel depth) using an UMAX 2100 scanner (Umax, Willich, Germany) in transmission mode as TIFF files and analyzed using the ImageMaster Platinum 7.0 software (GE Healthcare, Piscataway, NJ, USA). Each sample was analyzed by $2-\mathrm{DE}$ in at least three repetitions for further analysis. The abundance of each protein spot was estimated by calculating the percentage volume (\% vol). Only protein spots with significant and reproducible changes of at least 1.5 -fold, and deemed significant by Student's $t$-test at a level of $95 \%$, were accepted as differentially expressed. These spots were then subjected to MS/MS analysis. The standard error (SE) was calculated from at least three spots in replicate gels.

\subsection{In-Gel Digestion and Mass Spectrometry Analysis}

Selected protein spots were excised manually from the CBB stained gels, and in-gel digestion was performed as reported previously [65]. Tryptic peptides were analyzed uaing an ABI 4800 MALDI-TOF/TOF Plus mass spectrometer (Applied Biosystems, Foster City, CA, USA). Data were acquired in a positive MS reflector using a CalMix 5 standard to calibrate the instrument (ABI4800 Calibration Mixture). Both the MS and MS/MS data were integrated and processed using the GPS Explorer V3.6 software (Applied Biosystems, Foster City, CA, USA), with default parameters. Based on combined MS and MS/MS spectra, proteins were successfully identified based on $95 \%$ or higher confidence interval of their scores in the MASCOT V2.1 search engine (Matrix Science Ltd., London, $\mathrm{UK}$ ), using the following search parameters: NCBI nr (green plants) database, trypsin as the digestion enzyme, one missed cleavage site, fixed modifications of carbamidomethyl (C), partial modification of acetyl (protein $N$-term), oxidation (M), deamidated:18O(1) (NQ), dioxidation (W), 120 ppm for precursor ion tolerance, and $0.3 \mathrm{Da}$ for fragment ion tolerance. 


\section{Conclusions}

In the present study, we investigated chromium stress induced physiological responses, and proteomic changes in maize leaves. A total of 60 proteins were identified that were differentially expressed in short-term chromium stress-treated leaf samples. The $\mathrm{Cr}$ stress-responsive proteins identified using MS analysis were mainly involved in ROS detoxification and defense responses, photosynthesis and chloroplast organization, post-transcriptional processing of mRNA and rRNA, protein synthesis and folding, DNA damage responses, and the cytoskeleton, suggesting that plants modify their metabolism by reprogramming the expression of genes to adapt to $\mathrm{Cr}$ stress. These findings might increase our understanding of the physiological response to $\mathrm{Cr}$ stress in maize leaves at the molecular level.

\section{Acknowledgments}

This research was financially supported in part by grants from the National Natural Science Foundation of China (31070361), the Key Project of Chinese Ministry of Education (210266), the Education Department of Anhui Province Natural Science Research Key Project (KJ2012A215), the Fundamental Research Funds for the Central Universities (1112KYQN31); the National Training Programs of Innovation for Undergraduates (GCCX2013110017), and the National High Technology Research and Development Program of China (2012AA10A306).

\section{Conflict of Interest}

The authors declare no conflict of interest.

\section{References}

1. Pilon-Smits, E. Phytoremediation. Annu. Rev. Plant Biol. 2005, 56, 15-39.

2. Faisal, M.; Hasnain, S. Chromate resistant Bacillus cereus augments sunflower growth by reducing toxicity $\mathrm{Cr}(\mathrm{VI})$. J. Plant Biol. 2005, 48, 187-194.

3. Gbaruko, B.C.; Friday, O.U. Bioaccumulation of heavy metals in some fauna and flora. Int. J. Environ. Sci. Technol. 2007, 4, 197-202.

4. Scoccianti, V.; Crinelli, R.; Tirillini, B.; Mancinelli, V.; Speranza, A. Uptake and toxicity of Cr (Ш) in celery seedlings. Chemosphere 2006, 64, 1695-1703.

5. Gao, Y.; Xia, J. Chromium contamination accident in China: Viewing environment policy of China. Environ. Sci. Technol. 2011, 45, 8605-8606.

6. Wang, Y.T.; Xiao, C. Factors affecting hexavalent chromium reduction in pure cultures of bacteria. Water Res. 1995, 29, 2467-2474.

7. Clemens, S. Molecular mechanisms of plant metal tolerance and homeostasis. Planta 2001, 212, 475-486.

8. Manara, A. Plant Responses to Heavy Metal Toxicity. In Plants and Heavy Metals; Furini, A., Ed.; Springer: Berlin, Germany, 2012; pp. 27-53.

9. Shanker, A.K.; Cervantes, C.; Loza-Tavera, H.; Avudainayagam, S. Chromium toxicity in plants. Environ. Int. 2005, 31, 739-753. 
10. Shanker, A.K.; Djanaguiraman, M.; Venkateswarlu, B. Chromium interactions in plants: Current status and future strategies. Metallomics 2009, 1, 375-383.

11. Quaggiotti, S.; Barcaccia, G.; Schiavon, M.; Nicolé, S.; Galla, G.; Rossignolo, V.; Soattin, M.; Malagoli, M. Phytoremediation of chromium using Salix species: Cloning ESTs and candidate genes involved in the Cr response. Gene 2007,402, 68-80.

12. Dubey, S.; Misra, P.; Dwivedi, S.; Chatterjee, S.; Bag, S.; Mantri, S.; Asif, M.; Rai, A.; Kumar, S.; Shri, M.; et al. Transcriptomic and metabolomic shifts in rice roots in response to $\mathrm{Cr}(\mathrm{VI})$ stress. BMC Genomics 2010, 11, 648.

13. Sharmin, S.A.; Alam, I.; Kim, K.H.; Kim, Y.G.; Kim, P.J.; Bahk, J.D.; Lee, B.H. Chromium-induced physiological and proteomic alterations in roots of Miscanthus sinensis. Plant Sci. 2012, 187, 113-126.

14. Sharma, D.C.; Sharma, C.P.; Tripathi, R.D. Phytotoxic lesions of chromium in maize. Chemosphere 2003, 51, 63-68.

15. Labra, M.; Gianazza, E.; Waitt, R.; Eberini, I.; Sozzi, A.; Regondi, S.; Grassi, F.; Agradi, E. Zea mays L. protein changes in response to potassium dichromate treatments. Chemosphere 2006, $62,1234-1244$.

16. Prinsi, B.; Negri, A.S.; Pesaresi, P.; Cocucci, M.; Espen, L. Evaluation of protein pattern changes in roots and leaves of Zea mays plants in response to nitrate availability by two-dimensional gel electrophoresis analysis. BMC Plant Biol. 2009, 9, 113.

17. The UniProt Knowledgebase (UniProtKB). Available online: http://www.ebi.uniprot.org/ (accessed on 8 January 2013).

18. The Arabidopsis Information Resource (TAIR). Available online: http://www.arabidopsis.org/ (accessed on 8 January 2013).

19. Altschul, S.F.; Madden, T.L.; Schaffer, A.A.; Zhang, J.; Zhang, Z.; Miller, W.; Lipman, D.J. Gapped BLAST and PSI-BLAST: A new generation of protein database search programs. Nucleic Acids Res. 1997, 25, 3389-3402.

20. Qian, W.; Yu, C.; Qin, H.; Liu, X.; Zhang, A.; Johansen, I.E.; Wang, D. Molecular and functional analysis of phosphomannomutase (PMM) from higher plants and genetic evidence for the involvement of PMM in ascorbic acid biosynthesis in Arabidopsis and Nicotiana benthamiana. Plant J. 2007, 49, 399-413.

21. Hou, F.Y.; Huang, J.; Yu, S.L.; Zhang, H.S. The 6-phosphogluconate dehydrogenase genes are responsive to abiotic stresses in rice. J. Integr. Plant Biol. 2007, 49, 655-663.

22. Gao, F.; Zhou, Y.; Zhu, W.; Li, X.; Fan, L.; Zhang, G. Proteomic analysis of cold stress-responsive proteins in Thellungiella rosette leaves. Planta 2009, 230, 1033-1046.

23. Rocha, M.; Sodek, L.; Licausi, F.; Hameed, M.W.; Dornelas, M.C.; van Dongen, J.T. Analysis of alanine aminotransferase in various organs of soybean (Glycine max) and in dependence of different nitrogen fertilisers during hypoxic stress. Amino Acids. 2010, 39, 1043-1053.

24. Vieira Dos Santos, C.; Cuiné, S.; Rouhier, N.; Rey, P. The Arabidopsis plastidic methionine sulfoxide reductase $\mathrm{B}$ proteins. Sequence and activity characteristics, comparison of the expression with plastidic methionine sulfoxide reductase A, and induction by photooxidative stress. Plant Physiol. 2005, 138, 909-922. 
25. Dietz, K.J.; Jacob, S.; Oelze, M.L.; Laxa, M.; Tognetti, V.; de Miranda, S.M.; Baier, M.; Finkemeier, I. The function of peroxiredoxins in plant organelle redox metabolism. J. Exp. Bot. 2006, 57, 1697-1709.

26. Sachetto-Martins, G.; Franco, L.O.; de Oliveira, D.E. Plant glycine-rich proteins: A family or just proteins with a common motif? Biochim. Biophys. Acta 2000, 1492, 1-14.

27. Wen, R.; Newton, L.; Li, G.; Wang, H.; Xiao, W. Arabidopsis thaliana UBC13: Implication of error-free DNA damage tolerance and Lys63-linked polyubiquitylation in plants. Plant Mol. Biol. 2006, 61, 241-253.

28. Sarry, J.E.; Kuhn, L.; Ducruix, C.; Lafaye, A.; Junot, C.; Hugouvieux, V.; Jourdain, A.; Bastien, O.; Fievet, J.B.; Vailhen, D.; et al. The early responses of Arabidopsis thaliana cells to cadmium exposure explored by protein and metabolite profiling analyses. Proteomics 2006, 6, 2180-2198.

29. Kato, Y.; Sun, X.; Zhang, L.; Sakamoto, W. Cooperative D1 degradation in the photosystem II repair mediated by chloroplastic proteases in Arabidopsis. Plant Physiol. 2012, 159, 1428-1439.

30. Mittler, R. Abiotic stress, the field environment and stress combination. Trends Plant Sci. 2006, $11,15-19$.

31. Rapala-Kozik, M.; Wolak, N.; Kujda, M.; Banas, A.K. The upregulation of thiamine (vitamin B1) biosynthesis in Arabidopsis thaliana seedlings under salt and osmotic stress conditions is mediated by abscisic acid at the early stages of this stress response. BMC Plant Biol. 2012, 12, 2.

32. Davies, F.T.; Puryear, J.D.; Newton, R.J.; Egilla, J.N.; Grossi, J.A.S. Mycorrhizal fungi increase chromium uptake by sunflower plants: Influence on tissue mineral concentration, growth, and gas exchange. J. Plant Nutr. 2002, 25, 2389-2407.

33. Zhang, L.; Kato, Y.; Otters, S.; Vothknecht, U.C.; Sakamoto, W. Essential role of VIPP1 in chloroplast envelope maintenance in Arabidopsis. Plant Cell. 2012, 24, 3695-3707.

34. Lange, P.R.; Geserick, C.; Tischendorf, G.; Zrenner, R. Functions of chloroplastic adenylate kinases in Arabidopsis. Plant Physiol. 2008, 146, 492-504.

35. Gong, P.; Zhang, J.; Li, H.; Yang, C.; Zhang, C.; Zhang, X.; Khurram, Z.; Zhang, Y.; Wang, T.; Fei, Z.; Ye, Z. Transcriptional profiles of drought-responsive genes in modulating transcription signal transduction, and biochemical pathways in tomato. J. Exp. Bot. 2010, 61, 3563-3575.

36. Wang, L.; Ouyang, M.; Li, Q.; Zou, M.; Guo, J.; Ma, J.; Lu, C.; Zhang, L. The Arabidopsis chloroplast ribosome recycling factor is essential for embryogenesis and chloroplast biogenesis. Plant Mol. Biol. 2010, 74, 47-59.

37. Keunen, E.; Remans, T.; Bohler, S.; Vangronsveld, J.; Cuypers, A. Metal-induced oxidative stress and pant mitochondria. Int. J. Mol. Sci. 2011, 12, 6894-6918.

38. Dixit, V.; Pandey, V.; Shyam, R.V. Chromium ions inactivate electron transport and enhance superoxide generation in vivo in pea (Pisum sativum L. cv. Azad) root mitochondria. Plant Cell Environ. 2002, 25, 687-693.

39. Koussevitzky, S.; Suzuki, N.; Huntington, S.; Armijo, L.; Sha, W.; Cortes, D.; Shulaev, V.; Mittler, R. Ascorbate peroxidase 1 plays a key role in the response of Arabidopsis thaliana to stress combination. J. Biol. Chem. 2008, 283, 34197-34203.

40. Dowdle, J.; Ishikawa, T.; Gatzek, S.; Rolinski, S.; Smirnoff, N. Two genes in Arabidopsis thaliana encoding GDP-L-galactose phosphorylase are required for ascorbate biosynthesis and seedling viability. Plant J. 2007, 52, 673-689. 
41. Xiong, Y.; DeFraia, C.; Williams, D.; Zhang, X.; Mou, Z. Characterization of Arabidopsis 6-phosphogluconolactonase T-DNA insertion mutants reveals an essential role for the oxidative section of the plastidic pentose phosphate pathway in plant growth and development. Plant Cell Physiol. 2009, 50, 1277-1291.

42. Belenghi, B.; Acconcia, F.; Trovato, M.; Perazzolli, M.; Bocedi, A.; Polticelli, F.; Ascenzi, P.; Delledonne, M. AtCYS1, a cystatin from Arabidopsis thaliana, suppresses hypersensitive cell death. Eur. J. Biochem. 2003, 270, 2593-2604.

43. Zhang, X.; Liu, S.; Takano, T. Two cysteine proteinase inhibitors from Arabidopsis thaliana, AtCYSa and AtCYSb, increasing the salt, drought, oxidation and cold tolerance. Plant Mol. Biol. 2008, 68, 131-143.

44. Wei, Z.M.; Laby, R.J.; Zumoff, C.H.; Bauer, D.W.; He, S.Y.; Collmer, A.; Beer, S.V. Harpin, elicitor of the hypersensitive response produced by the plant pathogen Erwinia amylovora. Science 1992, 257, 85-88.

45. Mazzucotelli, E.; Mastrangelo, A.M.; Crosatti, C.; Guerra, D.; Stanca, A.M.; Cattivelli, L. Abiotic stress response in plants: When post-transcriptional and post-translational regulations control transcription. Plant Sci. 2008, 174, 420-431.

46. Burd, C.G.; Dreyfuss, G. Conserved structures and diversity of functions of RNA-binding proteins. Science 1994, 265, 615-621.

47. Gao, F. Minzu University of China, Beijing, China. Unpublished work, 2008.

48. Kim, J.S.; Jung, H.J.; Lee, H.J.; Kim, K.A.; Goh, C.H.; Woo, Y.; Oh, S.H.; Han, Y.S.; Kang, H. Glycine-rich RNA-binding protein 7 affects abiotic stress responses by regulating stomata opening and closing in Arabidopsis thaliana. Plant J. 2008, 55, 455-466.

49. Kwak, K.J.; Park, S.J.; Han, J.H.; Kim, M.K.; Oh, S.H.; Han, Y.S.; Kang, H. Structural determinants crucial to the RNA chaperone activity of glycine-rich RNA-binding proteins 4 and 7 in Arabidopsis thaliana during the cold adaptation process. J. Exp. Bot. 2011, 62, 4003-4011.

50. Kwak, K.J.; Kim, Y.O.; Kang, H. Characterization of transgenic Arabidopsis plants overexpressing GR-RBP4 under high salinity, dehydration, or cold stress. J. Exp. Bot. 2005, 56, 3007-3016.

51. Fu, Z.Q.; Guo, M.; Jeong, B.R.; Tian, F.; Elthon, T.E.; Cerny, R.L.; Staiger, D.; Alfano, J.R. A type III effector ADP-ribosylates RNA-binding proteins and quells plant immunity. Nature 2007, 447, 284-288.

52. Gerashchenko, M.V.; Lobanov, A.V.; Gladyshev, V.N. Genome-wide ribosome profiling reveals complex translational regulation in response to oxidative stress. Proc. Natl. Acad. Sci. USA 2012, 109, 17394-17399.

53. Salnikow, K.; Zhitkovich, A. Genetic and epigenetic mechanisms in metal carcinogenesis and cocarcinogenesis: Nickel, arsenic, and chromium. Chem. Res. Toxicol. 2008, 21, 28-44.

54. Nickens, K.P.; Patierno, S.R.; Ceryak, S. Chromium genotoxicity: A double-edged sword. Chem. Biol. Interact. 2010, 188, 276-288.

55. Machado, C.R.; Praekelt, U.M.; de Oliveira, R.C.; Barbosa, A.C.; Byrne, K.L.; Meacock, P.A.; Menck, C.F. Dual role for the yeast THI4 gene in thiamine biosynthesis and DNA damage tolerance. J. Mol. Biol. 1997, 273, 114-121. 
56. Ruzicka, D.R.; Kandasamy, M.K.; McKinney, E.C.; Burgos-Rivera, B.; Meagher, R.B. The ancient subclasses of Arabidopsis Actin Depolymerizing Factor genes exhibit novel and differential expression. Plant J. 2007, 52, 460-672.

57. Jiang, C.J.; Weeds, A.G.; Hussey, P.J. The maize actin-depolymerizing factor, ZmADF3, redistributes to the growing tip of elongating root hairs and can be induced to translocate into the nucleus with actin. Plant J. 1997, 12, 1035-1043.

58. Fan, T.; Zhai, H.; Shi, W.; Wang, J.; Jia, H.; Xiang, Y.; An, L. Overexpression of profilin 3 affects cell elongation and F-actin organization in Arabidopsis thaliana. Plant Cell. Rep. 2013, $32,149-160$.

59. Taketani, S.; Adachi, Y.; Kohno, H.; Ikehara, S.; Tokunaga, R.; Ishii, T. Molecular characterization of a newly identified heme-binding protein induced during differentiation of urine erythroleukemia cells. J. Biol. Chem. 1998, 273, 31388-31394.

60. Song, L.; Shi, Q.M.; Yang, X.H.; Xu, Z.H.; Xue, H.W. Membrane steroid-binding protein 1 (MSBP1) negatively regulates brassinosteroid signaling by enhancing the endocytosis of BAK1. Cell. Res. 2009, 19, 864-876.

61. Divi, U.K.; Rahman, T.; Krishna, P. Brassinosteroid-mediated stress tolerance in Arabidopsis shows interactions with abscisic acid, ethylene and salicylic acid pathways. BMC Plant Biol. 2010, 10, 151.

62. Majeran, W.; Friso, G.; Ponnala, L.; Connolly, B.; Huang, M.; Reidel, E.; Zhang, C.; Asakura, Y.; Bhuiyan, N.H.; Sun, Q.; Turgeon, R.; van Wijk, K.J. Structural and metabolic transitions of C4 leaf development and differentiation defined by microscopy and quantitative proteomics in maize. Plant Cell 2010, 22, 3509-3542.

63. Yan, S.P.; Zhang, Q.Y.; Tang, Z.C.; Su, W.A.; Sun, W.N. Comparative proteomic analysis provides new insights into chilling stress responses in rice. Mol. Cell. Proteomics 2006, 5, 484-496.

64. Bates, L.S.; Waldren, R.P.; Tears, I.D. Rapid determination of free proline in water stress studies. Plant Soil 1975, 39, 205-207.

65. Katayama, H.; Nagasu, T.; Oda, Y. Improvement of in-gel digestion protocol for peptide mass fingerprinting by matrix-assisted laser desorption/ionization time-of-flight mass spectrometry. Rapid Commun. Mass Spectrom. 2001, 15, 1416-1421.

(C) 2013 by the authors; licensee MDPI, Basel, Switzerland. This article is an open access article distributed under the terms and conditions of the Creative Commons Attribution license (http://creativecommons.org/licenses/by/3.0/). 